\title{
REINVENCIÓN DE LA GUERRA DE LOS MIL DÍAS (1899-1902) EN TRES NOVELAS COLOMBIANAS
}

\author{
AlBerto BEJARANO ${ }^{1}$ \\ Instituto Caro y Cuervo de Colombia \\ otrasinquisiciones@hotmail.com \\ ORCID: 0000-0002-6958-3043
}

\section{RESUMEN}

En nuestro artículo presentamos tres visiones literarias sobre la Guerra de los Mil Días en Colombia (1899-1902) que terminará con la pérdida de Panamá y la intervención de Estados Unidos con el fin de construir el Canal interoceánico. La guerra, la más larga de las guerras civiles en Colombia, marcó el curso de los años por venir y podría hablarse de un germen de la Violencia contemporánea que aún no cesa. Fue uno de los acontecimientos fundamentales para escritores como Gabriel García Márquez y legendarios personajes como el coronel Aureliano Buendía.

PALABRAS CLAVE: Colombia, literatura comparada, Guerra de los Mil Días, García Márquez.

\section{REINVENTION OF THE THOUSAND DAY WAR (1899-1902) IN THREE COLOMBIAN NOVELS}

\section{ABSTRACT}

In our article we present three literary visions about the Thousand Days War in Colombia (1899-1902) that will end with the loss of Panama and the intervention of the United States in order to build the inter-oceanic Canal. The war, the longest of the civil wars in Colombia, marked the course of the years to come and one could speak of a germ of contemporary Violence that has not ceased. It was one of the fundamental events for writers such as Gabriel García Márquez and legendary characters such as Colonel Aureliano Buendía.

KEYWORDS: Colombia, comparative literature, guerra de los mil días, García Márquez.

Nuestro eje de trabajo será la exploración de la memoria en Colombia como espacio de consensos y disensos históricos con respecto a la valoración estética de la Guerra de los Mil Días (1899-1902), expresada en tres novelas colombianas, caracterizadas por explorar otros lenguajes e interactuar con discursos divergentes sobre lo político y lo cultural. Nuestras preguntas apuntan a plantearnos, ¿qué discursos estéticos y políticos subyacen a las representaciones documentales y ficcionales sobre la memoria y el duelo en Colombia?, ¿de qué forma podemos interpretar las nuevas narrativas sobre lo político en el contexto de cambio cultural creciente en Colombia?, ¿cómo

\footnotetext{
${ }^{1}$ Doctor en filosofía de la Universidad París 8. Investigador y docente en literatura comparada en el Instituto Caro y Cuervo de Colombia. Escritor de cuentos.
} 
explorar otras realidades políticas a través de miradas alternativas sobre lo rural, lo urbano, el desplazamiento forzado, la diversidad étnica, religiosa, de género, o de disidencia?, ¿qué tipo de conceptos políticos se ponen en juego en los discursos actuales sobre memoria y duelo en un campo estético y que reflexiones podemos tejer a partir de ellos?

Para pensadores como Giorgio Agamben, lo contemporáneo es lo que llega demasiado pronto o demasiado tarde, es decir, genera interrogantes sobre el pasado y abre nuevas inquietudes en las sociedades actuales, mediadas por la velocidad de los cambios en la cultura política, en la crisis de la representación $\mathrm{y}$ en las nuevas formas de sociabilidad que ponen a prueba los contratos sociales tradicionales. Para el caso colombiano, marcado por una sucesión casi endémica de guerras civiles y conflictos armados durante doscientos años, repensar el pasado significa buscar y dialogar con fuentes diversas de interpretación que reformulen el relato oficial dominante sustentado en la idea de una predisposición colombiana por la violencia y en tiempos más recientes (hasta 2010, de nuevo desde 2018) expresados como «amenazas terroristas». Se calcula que para la época de La Violencia (1946-1958) se asesinaron alrededor de 300.000 personas, cifra casi igual a la del conflicto armado de los últimos cincuenta años.

Agamben justamente dialoga con fuentes amplias, que van de la fotografía, a los archivos, a las artes, la literatura, el teatro, y por supuesto, a los textos clásicos y modernos de la filosofía. Para Agamben,

el totalitarismo moderno puede ser definido como la instauración, a través del estado de excepción, de una guerra civil legal que permite la eliminación física no solo de los adversarios políticos, sino de categorías enteras de ciudadanos que por cualquier razón no pueden ser integrados en el sistema político. (Agamben 2005: 54)

En Colombia, además de las guerras civiles del siglo XIX, se vivió en estado de excepción de forma casi ininterrumpida entre 1886 y 1991, lo que autorizaba al Estado no solamente «a la eliminación física de los adversarios políticos», sino a unificar y hegemonizar de diferentes formas los relatos de construcción de memoria sobre los orígenes y expresiones del conflicto social y político. Solo a partir de 1991, con una nueva constitución, se restringió el estado de excepción (prácticamente no se ha usado desde entonces, aunque esto no quiera decir que no se continúe con políticas de exterminio político, expresada en el año 2019 con el asesinato de más de 120 indígenas y más de mil líderes sociales y reinsertados de la antigua guerrilla FARC). A pesar de ello, desde 1991, se reconoce una nación pluriétnica y multicultural, que involucra cosmogonías distintas (alrededor de las 86 lenguas oficiales reconocidas), así como de la interacción con historias de vida marcadas por el conflicto armado en sus múltiples efectos, bien sea de desarraigo, exilio, despojo, o duelo. Ahora gradualmente se reconoce que sé es ciudadano, víctima/victimario/mujer/afrodescendiente... Sin embargo, en tiempos de la 
Guerra de los Mil Días (1899-1902) se trataba de una guerra a muerte. A partir de la constitución de 1991, se ha intentado enfrentar el reto de reconocernos como pluriétnicos y multiculturales, lo que significa entre otras cosas reconfigurar las fuentes, relatos y narrativas sobre quienes somos como nación, permanentemente en conflicto. Si nos fijamos, por ejemplo, en la primera sala que se renovó en el Museo Nacional, «memoria y nación» (2014) observamos un mosaico de subjetividades e identidades colectivas en plena diversidad y en los pasillos laterales entramos en contacto con piezas culturales como el tejido de las tejedoras de Mampuján, Bolívar, testimonio de la violencia.

Como lo sugiere el crítico literario brasileño Horacio Campo, necesitamos como latinoamericanos seguir construyendo nuevas categorías de estudio que nos acerquen entre nosotros, a pensar temas comunes, sin perder de vista las singularidades nacionales que él opta por llamar, miradas superregionales:

cercado por países de origen hispánico, Brasil ha procurado cada vez más enfatizar sus semejanzas históricas, étnicas y culturales con ellos. El asunto, la cuestión latinoamericana, prácticamente ignorada en el siglo XIX por la cultura brasileña, salvo algunas excepciones, se volvió vital para nosotros, por lo menos desde los años cincuentas o sesentas... la literatura hispanoamericana es cada vez más parte de aquello que podríamos llamar canon literario brasileño actual... a pesar de sus numerosas limitaciones, la universidad brasileña me parece mejor preparada que su contrapartida hispanoamericana para suscitar un movimiento de reciprocidad, un rompimiento de la inercia... la literatura comparada, como espacio conceptual, representa en sí un instrumento valioso de conocimiento mutuo, de reciprocidad intrínseca. (Campo 1998: 415)

Uno de los cauces posibles para una literatura comparada latinoamericana que se cruce con Brasil es el acercamiento a la novela histórica como subgénero narrativo que aborda cuestiones críticas del estudio de las naciones y a la vez de las singularidades superregionales de las que hablaba Campo en su célebre trabajo producido y publicado en México. Como lo enfatiza el escritor colombiano Fernando Cruz Kronfly, -quien escribiera una de las mejores novelas históricas sobre Bolívar-, es necesario delimitar y repensar los confines y posibilidades de las novelas históricas ya que:

un gran riesgo de la novela histórica consiste en permanecer prisionera del alarde de información, sin otras metas distintas. Llenarse de datos sabiendo que por más esfuerzos que se hagan éstos nunca serán satisfactorios para los especialistas, y que, incluso, los datos que un historiador nos proporciona no siempre habrán de coincidir con los del autor siguiente; el riesgo aquí consiste en que el escritor no sea capaz de trascender el acontecimiento para situarse en la perspectiva de los universales, acudiendo a los recursos de la metáfora y el símbolo, a la presencia de las ideas y el pensamiento. (Cruz 1994: 71)

Teóricos contemporáneos como Rancière y Didi Huberman se encaminan en esta misma dirección, al señalar que el espacio abierto de la ficción, lejos de afectar negativamente los estudios históricos, nutren y alientan más miradas 
críticas sobre el pasado (y el presente), planteándonos ante todo nuevas preguntas más que aparentes respuestas. Para Rancière:

No es en los encadenamientos de la historia donde hay que buscar el tenor ficcional. Hay que buscar ese tenor, que se busca siempre en el interior, afuera, "alrededor" de la historia...el sentido de la historia está en lo que rodea a la historia, es decir el medio del sentido, el medio de las acciones. (Rancière 2014: 38)

Zarparemos de una página memorable de Cien años de Soledad de García Márquez en la que se narra el final de la Guerra de los Mil Días:

Esta guerra ha acabado con todo [...] El martes del armisticio amaneció tibio y lluvioso. El coronel Aureliano Buendía apareció en la cocina antes de las cinco y tomó su habitual café sin azúcar [...] el acto se celebró a veinte kilómetros de Macondo, a la sombra de una ceiba gigantesca en torno a la cual había de fundarse más tarde el pueblo de Neerlandia [...] El coronel Aureliano Buendía llegó en una mula embarrada. Estaba sin afeitar, más atormentado por el dolor de los golondrinos que por el inmenso fracaso de sus sueños, pues había llegado al término de toda esperanza, más allá de la gloria y de la nostalgia de la gloria [...] el acto duró apenas el tiempo indispensable para que se estamparan las firmas [...] Sin inmutarse, el coronel Aureliano Buendía firmó la primera copia. (García Márquez 1985: 226)

Es una cita extensa, de uno de los pasajes más memorables de la novela, en cuanto muestra el mundo sin sentido que se vive tras la disolución progresiva de Macondo, gran metáfora de Colombia y sus guerras civiles. La figura de la mula embarrada enmarca en buena medida lo que significa recorrer el país en las guerras civiles, acaso el único momento donde gentes de todas partes se conocían y compartían sus culturas y costumbres.

Como lo recuerda el escritor y crítico literario colombiano Pablo Montoya:

García Márquez considera que no hay período más atractivo de la historia colombiana que la segunda mitad del siglo XIX. Es el período de la adolescencia republicana, en el que las diferencias entre conservadores y liberales, según el Nobel, se dieron más nítidas que en ningún otro momento. (Montoya 2010: 54)

La guerra era la única forma de conocer el país, de atravesar diversas y extrañas geografías que la mayor. Es un denominador común de los conflictos, una postal irónica sobre pueblos y gentes que se enfrentan a muerte, siendo en muchos casos vecinos o semejantes en términos de etnias, regiones $\mathrm{o}$ costumbres diversas. La experiencia de la guerra no responde solamente al hecho de poner a prueba ideologías, disputas territoriales e intereses personales. La guerra en Colombia ha sido el escenario principal en que se han expresado los disensos sociales y políticos frente a la imposición del estado de excepción. Si bien es cierto, Colombia se precia de ser uno de los países latinoamericanos que menos padeció las dictaduras, no puede perderse de vista que es el que más convivió con un estado de excepción casi permanente, con consecuencias no solo similares (en cuanto al ejercicio de prácticas abiertamente 
violadoras de los derechos humanos, como la tortura y la desaparición forzada) sino más extendidas en el tiempo.

La tropa era una plaga de langosta que deja la tierra desnuda a su paso. las dianas tocaban, los toneros tiraban del parque, las columnas de escolta avanzaban por un camino que cambiaba de colores y por lugares que se parecían a sus nombres: Sietelagunas...las termópilas de Iscalá, en Mejue... Altoviento... Aguahirviendo... Ventaquemada, donde había una casa calcinada por donde ya había pasado hacía años el vendaval de la guerra... Lagunaplata, El Horcón... Casasola... Panzadeburro... Casasciegas... El crepúsculo... El nido... la laguna negra... el rebozo... perseguían así el rastro del general Uribe Uribe: casas quemadas, restos de hogueras hechas con frailejones penetrantes, casquillos de balas de recalce $\mathrm{y}$, a la sombra de un árbol sin hojas, una pira de cadáveres de hombres muertos en combate cuyos cuerpos calcinados todavía humeaban al atardecer de un sol que nublaba como el ojo de un guañuz. (Ferreira 2018: 96)

Desde un enfoque internacional, la Guerra de los Mil Días en Colombia (1899-1902) está a mitad de camino de la Guerra civil norteamericana (18611865) y de la revolución mexicana (1910-1920). Si observamos las fotografías que recogen su tiempo, las imágenes se asocian a los relatos de estos dos conflictos que anteceden a la guerra casi totalmente mecanizada del siglo Xx. Tienen en común la duración prolongada y el carácter de guerra de guerrillas que tomaría cada conflicto. Las carnicerías propias de las guerras tienen su coronación en el caso de la Guerra de los Mil Días el monumento de Palonegro, hecho completamente de osamentas de los combatientes, emplazado en el actual aeropuerto de Bucaramanga y que, hasta tiempos recientes relucía. ${ }^{2}$

La guerra tuvo moviles externos e internos. En cuanto a los primeros, había una tendencia de movimientos liberales en la región, liderados por caudillos en Venezuela y Ecuador, - quienes terminarían prestando importante auxilio a los revolucionarios liberales colombianos - , y, sin duda la inminente intervención de Estados Unidos en Panamá para dominar su territorio y hacerse con los derechos de construcción y monopolio del canal de Panamá, incentivaron la guerra y la prolongaron. No es un detalle menor que los últimos combates se hayan librado en el Istmo y el tratado de paz entre conservadores y liberales se haya firmado en el buque de guerra norteamericano, Wisconsin, fondeado en aguas panameñas en noviembre de 1902. Un años después se produciría la intervención norteamericana e independencia de Panamá. En cuanto a las causas internas de la guerra, podemos señalar de manera sintética, en primer lugar, la aplicación del estado de excepción desde la nueva constitución de 1886 que suprimió las libertades de expresión, de prensa y abolió el delito político, entre muchos otros temas. Igualmente, la guerra se concentró en las regiones más prosperas de Colombia, ligadas al cultivo emergente del café, lo que generó nuevas demandas y expresiones sociales. La

\footnotetext{
2 Ver la excelente crónica, Una rosa violenta de Arturo Guerrero, disponible en: $<$ https://www.elespectador.com/noticias/cultura/una-rosa-violenta-i-articulo-558226>.
} 
guerra se concentró sobre todo en Cundinamarca, Santander, el caribe y Panamá. Justamente estos son los epicentros de la narración de las tres novelas que estudiamos:

- José Antonio Osorio Lizarazo. El camino de la sombra, Aguilar, Madrid, 1963

- Rafael Baena. La guerra perdida de indio Lorenzo, Alfaguara, Bogotá, 2015

- Daniel Ferreira. El año del sol negro, Alfaguara, Bogotá, 2018

Señalemos brevemente que Rafael Baena fue periodista y se especializó en escribir novelas históricas (escribió una novela sobre la independencia); Osorio Lizarazo fue también periodista y se especializó en narrar la Violencia, y Ferreira es un escritor actual que se ha ocupado de las violencias recientes. Hay que subrayar que tanto Osorio como Baena hicieron una trilogía sobre la guerra de los Mil Días (Servidumbre y Fuera de la ley en Osorio; Tanta sangre vista, La bala vendida), -solo nos ocuparemos de una-, al igual que Baena, -solo nos detendremos en una. Ferreira llama a su literatura una pentalogia de la violencia en Colombia, ya ha publicado tres, y no se sabe aún sobre qué periodo se ocuparán las dos restantes.

Podría decirse que durante el turbulento siglo XIX (de 1830 a 1902), Colombia vivió una sola, larga, guerra civil, que apenas por momentos se detenía para tomar (más) impulso. Fueron en total 9 guerras civiles (14 locales, dos internacionales, tres golpes de Estado). La última de ellas, la más larga y sangrienta (150.000 mil muertos para una población de 4 millones) y con mayores connotaciones internacionales ${ }^{4}$ fue la de Los Mil Días. No sería aventurado señalar que inició realmente en 1895, con una breve guerra de dos meses, o incluso en $1885^{5}$. El embrollo, sin duda giró en torno, sobre todo, de Panamá:

Me dediqué a caminar por el laberinto de calles de aquel asombroso caleidoscopio de culturas (Panamá), escenario de hermosas casas multicolores en el que convivían en armonía todas las razas del planeta, incluidas algunas venidas desde lugares tan remotos como India, Etiopia, Zanzíbar, y por supuesto, China. Muchas familias chinas descendían de los obreros, - es un decir, porque en realidad fueron tratados como esclavos - que construyeron el ferrocarril de Panamá. (Baena 2015: 152)

El trabajo de investigación más importante que se ha hecho hasta el momento fue la biblioteca sobre Narrativas de las guerras civiles colombianas en nueve tomos, por la Universidad Industrial de Santander (una de las regiones

${ }_{3}$ Para Osorio Lizarazo Cundinamarca, para Rafael Baena Panamá, para Daniel Ferreira Santander.

${ }^{4}$ Estados Unidos, Venezuela, Ecuador, Nicaragua, El Salvador, Francia, Chile...

5 «Con ello el conflicto (de 1885) se extendió al Cauca, a la costa, a Antioquia, al Tolima y a Cundinamarca: prácticamente a todo el país, y duró más de un año. Intervinieron incluso, a favor del gobierno, los buques de la escuadra norteamericana que custodiaban en el istmo la vía férrea de la Panama Railroad Company, que cañonearon la ciudad de Colón y finalmente supervigilaron en Cartagena la entrega de las tropas liberales» (Caballero 2018: 98). 
más afectadas por la guerra), entre 2004 y 2006, que recoge estudios y la compilación de novelas destacadas, como la de Osorio que aquí recogemos. Es un gran esfuerzo editorial que desafortunadamente tiene poca circulación y reconocimiento. ${ }^{6}$ Podría decirse que las narrativas sobre la última guerra civil declarada en Colombia ocuparían un cuarto lugar en cuanto interés de los escritores colombianos. El primero es sin duda el periodo de La Violencia, el segundo Bolívar y las guerras de independencia, el tercero las violencias más recientes ligadas al narcotráfico.

\section{Como lo plantea el crítico Gutiérrez Girardot:}

El conflicto entre modernidad y tradición fue dirimido existencialmente, si se puede decir así, como guerra civil. Este conflicto acuñó especialmente en Colombia toda la vida política y social de modo tan penetrante como decisivo que dividió al país en dos bandos. Conservador y liberal no era solo o sobre todo posiciones políticas, sino que llegaron a ser los contenidos de la identidad individual y familiar...de esta tensión surgió y debe surgir una revolución. En García Márquez esta violencia es un fundamento de la historia y la sociedad colombiana. (Gutiérrez 2011: 241)

Es por ello, agrega Gutiérrez Girardot con plena justeza, que la gran novela colombiana es Cien años de Soledad que, inicia en El Coronel no tiene quien le escriba, con la sombra errante del coronel Aureliano Buendía... Como lo sintetiza el escritor Antonio Caballero (nieto de un general liberal durante la Guerra):

Fue la más larga y sangrienta de las guerras civiles. Desde 1899 hasta 1902 se combatió en casi todo el país, exceptuadas las regiones despobladas de la Amazonia y el departamento de Antioquia, casi homogéneamente conservador, en donde el alzamiento liberal fue aplastado en dos semanas. Se combatió en las montañas y en los ríos, en los dos mares, en las selvas del Chocó y en los desiertos de la Guajira. Los muertos fueron más de cien mil: más que en todas las guerras del siglo XIX sumadas, para una población total de unos cuatro millones de habitantes. Participaron en apoyo de los insurrectos, con armas y ocasionalmente con tropas, los países vecinos con gobiernos liberales: Venezuela (Cipriano Castro), el Ecuador (Eloy Alfaro) y Nicaragua (José Santos Zelaya). Y en apoyo del gobierno conservador intervinieron los Estados Unidos (Teodoro Roosevelt), que en Panamá frustraron las acciones del ejército liberal con el pretexto de defender el ferrocarril y las instalaciones del futuro Canal, entonces en construcción por una compañía francesa. (Caballero 2018: 103)

En una de las novelas que comentaremos, El camino de la sombra de Osorio Lizarazo, se sugiere que la Guerra en Colombia es una sola:

la revolución (liberal de 1895) quedó batida y las últimas fuerzas en Capitanejo, tuvieron que entregarse al jefe conservador, general Rafael Reyes. Y bajo el signo doloroso del desastre, el brillante ejército de Chiquinquirá quedó disuelto. - Pero la próxima no nos la ganan, mamá, terminó Feliciano, indicando que la rebelión palpitaba en el ambiente

\footnotetext{
6 Para una mirada más amplia sobre novelas de las guerras civiles en Colombia, tener en cuenta obras de Saturnino Restrepo, Marroquín, Juan Gabriel Vásquez, etc. Ver David Jiménez, Pablo Montoya.
} 
nacional. Antes de separarnos, todos juramos que regresaríamos al campo de batalla. El Gobierno conservador trata a todos los liberales como asesinos, como a parias, como a apartidas. ¡Volveremos a pelear hasta que logremos el triunfo de la justicia y el derecho! (Osorio Lizarazo 2014: 331)

Parafraseando el poema de Silva, diríamos que la guerra, como la noche, «era una, era una, era una sola sombra larga». Si dejamos de lado los testimonios de los protagonistas, testigos o contemporáneos de la Guerra de los Mil Días, e incluso de quienes escribieron los primeros acercamientos más ficcionales en las primeras décadas del siglo $\mathrm{XX},{ }^{7}$ podría decirse que a partir de finales de la década de 1950 se podría pensar un posible canon sobre la guerra. La novela fundadora sería El Coronel no tiene quien le escriba de García Márquez (1957). En esta novela esencial en la obra de Gabo, aparece en las conversaciones e insomnios fantasmales la figura ejemplar del coronel Aureliano Buendía (uno de los futuros personajes trascendentales de Cien años de soledad):

El coronel se alarmó. Como tesorero de la revolución en la circunscripción de Macondo había realizado un penoso viaje de seis días con los fondos de la guerra civil en dos baúles amarrados al lomo de una mula. Llegó al campamento de Neerlandia arrastrando la mula muerta de hambre media hora antes de que se firmara el tratado. El coronel Aureliano Buendía -intendente general de las fuerzas revolucionarias en el litoral atlántico- extendió el recibo de los fondos e incluyó los dos baúles en el inventario de la rendición $[\ldots]$

- ¿Con quién hablas

- Con nadie, - dijo el coronel. Estaba pensando que en la reunión de Macondo tuvimos razón cuando le dijimos al coronel Aureliano Buendía que no se rindiera. Eso fue lo que echó a perder el mundo [...]

Se acordó de Macondo. El coronel esperó diez años a que se cumplieran las promesas de Neerlandia. En el sopor de la fiesta vio llegar un tren amarillo y polvoriento con hombre y mujeres y animales asfixiándose de calor, amontonados hasta en el techo de los vagones. (García Márquez 2010: 49)

Neerlandia fue uno de los dos tratados que puso fin a la Guerra de los Mil Días (el otro fue el del Wisconsin, tratado en las novelas de Baena). El coronel Buendía está inspirado en el jefe liberal Rafael Uribe Uribe, quien «esperó diez años» según Gabo, para... ser asesinado en una calle de Bogotá, como senador, desarmado, en 1914. Al igual que la gran mayoría de gentes que dejan las armas en Colombia, como está ocurriendo en el último año y medio. Si retomamos las ideas de Agamben señaladas al inicio de este artículo sobre el estado de

\footnotetext{
7 «La narrativa sobre las guerras civiles colombianas del siglo XIX, escrita casi al mismo tiempo que se blandían los machetes, constituye una de las manifestaciones literarias de Colombia que en la medida que es objeto de estudio, devela una estructura articular en cuanto a las imágenes poéticas, el juego de anacronías, la descripción, la permanencia de ciertos recursos clásicos, su conexión con la novela histórica y la interpretación que hace del momento histórico, la cual obedece en ocasiones a una mentalidad romántica y en otros casos es una manifestación del hastío de años de conflicto» (Atehortua 2004: 51).
} 
excepción y tratamos de repensar la Guerra de los Mil Días en la hora actual del país, a través de las novelas que comentamos, podemos evidenciar que el disenso político es algo que sigue siendo cuestionado en Colombia y por ello mismo, aún hoy en día, a pesar de los esfuerzos por consolidar un estado más democrático, se siguen presentando ejecuciones extrajudiciales (mal llamados «falsos positivos») y el Estado emplea técnicas y métodos indiscriminados contra la población civil, so pretexto de enfrentarse «a sangre y fuego» a los enemigos internos. A inicios de noviembre de 2019 se conoció que en agosto pasado el ejercito bombardeó un campamento de entrenamiento de una de las disidencias de las FARC, en el que fueron asesinados ochos niños. El hecho llevó a una moción de censura del ministro de Defensa y a su renuncia. En otras palabras, comprender con más matices el desarrollo de la Guerra de los Mil Días y las formas de hacer la guerra, puede iluminar nuestro presente, para darnos cuenta de los usos del terror y del empleo de la violencia contra los civiles, como una continuidad histórica de los conflictos políticos en el país. En la Guerra de los Mil Días, el gobierno conservador se preciaba de asesinar prisioneros políticos en la cárcel como una manera de aterrorizar a los «contrarios».

Al elegir para este artículo, tres novelas de tres autores disímiles, en su formación, poética y procedencia, nos damos cuenta de que al menos uno de los personajes centrales de las novelas, deambula buscando unirse a las fuerzas liberales, bien sea en Cundinamarca, Santander o Panamá. Veamos el inicio de cada una de ellas. La primera, El camino de la sombra de José Antonio Osorio Lizarazo (1963), se concentra en los efectos de la guerra en quienes están en las retaguardias de los ejércitos (mujeres y familiares):

Las noticias que llegaban a la capital sobre el proceso de la guerra eran indecisas e incoherente, Sabíase que se luchaba vigorosamente en Santander, en el Tolima y en la costa. Se mencionaban los nombres de los grandes caudillos. El General Uribe Uribe alcanzaba gloriosas victorias, cuyo fragor traspasaba la distancia y trepidaba en Bogotá. El general Benjamin Herrera comandaba en el Pacífico y en Panamá un poderoso ejército. $\mathrm{Y}$ en el Tolima un grupo de capitanes invictos dejaban a su paso un reguero de proezas. El nombre del negro Marín vibraba como una clarinada de espanto y se cotejaba con el de Urias Romero, cuyo valor y cuya crueldad denunciaban el apasionado y primitivo ímpetu de sus convicciones políticas. (Osorio 1963: 381)

La segunda novela, La guerra perdida de indio Lorenzo, de Rafael Baena (2015), gira en torno de la vida cotidiana de un guerrillero liberal en Panamá:

Nosotros éramos mitad soldados y mitad espantos, en el sentido de que dedicábamos buena parte de nuestro tiempo a meterle miedo a los poblados de Penonomé y las haciendas de los alrededores mediante el expediente de gritar y emitir ruidos tenebrosos en medio de las noches, logrando de esa forma alterar sus nervios y hacerles sentir que si no nos tomábamos la localidad era porque no queríamos, pero que en cualquier momento acataríamos sin piedad. (Baena 2015: 80) 
La tercera novela, El año del sol negro de Daniel Ferreira (2018) se ocupa de la vida cotidiana de otro guerrillero liberal, pero esta vez en Santander:

\begin{abstract}
Caminó un tiempo sin rumbo, por callejuelas barridas de viento. La ciudad estaba bajo alarma por la llegada inminente de los ejércitos. Mulas atadas a las fallebas clavadas en las tapias. Perros azorados. Calles aromatizadas a estiércol seco, a fogón, a hierba macerada, a chocolate hirviendo, a pan tibio, a hojas de tamal, a sopa de vísceras, a orines de borracho. El cielo, cargado de bruma, amenazaba con las primeras gotas de una lluvia que no se desataba. En la calle de los extranjeros, las puertas de los almacenes estaban cerradas con doble lacre, y de dos casas pertenecientes a reconocidas familias simpatizantes del gobierno salían la servidumbre y los patrones con niños y animales domésticos y ropones de junco trenzado, subían corotos y enseres de valor al lomo de las mulas, lacraban la puerta y partían hacia el sur, donde según los boletines de guerra se había refugiado el gobierno de la Provincia. (Ferreira 2018: 25)
\end{abstract}

Destaquemos que en Baena y Ferreira, las dos narraciones provienen (como lo subrayan los propios autores en los prólogos) de reconstrucciones de testimonios orales de sus abuelos. Allí radica uno de los grandes aportes de estas novelas para trazar un puente entre la historia del siglo XIX y la actual. Siguiendo la huella de García Márquez (quien también partió de los testimonios orales de su abuelo como combatiente liberal al lado de Uribe Uribe), los nuevos narradores transitan hacia la ficción a través de la microhistoria y al mismo tiempo interrogan nuestro tiempo. Podríamos concluir señalando que la Guerra de los Mil Días es un espejo, un teatro en el que podemos leer también nuestra actualidad, no solo para detectar los aspectos recurrentes de la violencia en Colombia (en especial el ataque indiscriminado contra civiles por parte del Estado) sino también para destacar la relación entre literatura e historia, en particular con respecto a la historia oral y regional como una fuente de gran riqueza para abrir otras sendas de comprensión del país.

\title{
BIBLIOGRAFÍA
}

Agamben, G. (2000), Lo que queda de Auschwitz, Barcelona, Pretextos.

ATEHORTUA, A. (2004), «Una narrativa del engaño», en Narrativas de las guerras civiles colombianas, España, G., vol. 2, Bucaramanga, UIS.

BAENA, R. (2015), La guerra perdida del indio Lorenzo, Bogotá, Alfagura.

CABAllero, A. (2018), Historia de Colombia y su oligarquías, Bogotá, Ed Crítica.

CAMPO, H. (1998), Mar abierto, ensayos sobre literatura brasileña, portuguesa $e$ hispanoamericana, México, FCE.

CRUZ KRONFLY, F. (1994), «Ficción y novela histórica», en Literatura colombiana hoy, Kohut Karl, Iberoamericana, Frankfurt, 150-161.

Didi-Huberman, G. (2017), Cascas, Sao Paulo, Ed 34.

GARcía MÁrQueZ, G. (1985), Cien años de soledad, Madrid, Espasa.

GARCíA MÁRQueZ, G. (2010), El coronel no tiene quien le escriba, Bogotá, Norma. 
GUTIÉRREZ GIRARDOT, R. (2011), «La imagen de Colombia en Cien años de soledad», en Ensayos sobre literatura colombiana I, Gutiérrez Girardot, R., Medellín, Unaula, 4056.

GUERRERO, A. La rosa violenta [en línea]. Bogotá: El Espectador, 2 de mayo de 2015 [Consulta: 3 de noviembre de 2019]. Disponible en: $<$ https://www.elespectador.com/noti cias/cultura/una-rosa-violenta-i-articulo-558226>.

JARAMILLO, M. (2000), Literatura y cultura, narrativa colombiana del siglo XX (tres tomos), Bogotá, Min Cultura.

JIMÉNEZ, D. (2009), Historia de la crítica literaria en Colombia, Bogotá, UN.

MARQUES, R. (2015), Arquivos literarios, Belo Horizonte, Editora UFMG.

MONTOYA, P. (2009), Novela histórica en Colombia, 1988-2008, Medellín, Editorial Universidad de Antioquia.

OSORIO LIZARAZO, J. (2014), El camino en la sombra, Bogotá, Laguna libros.

RANCIÈRE, J. (2014), El hilo perdido, Buenos Aires, Manantial.

RAMíREZ, J. G. (2011), «Una comparación cuantitativa de las guerras civiles colombianas, 1830-2010», Anal. político, 24(72), 3-21. Disponible en: $<$ https://revistas.unal.edu.co/index.php/anpol/article/view/43689/45504>.

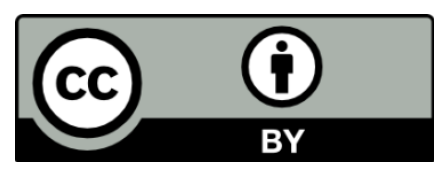

Los textos publicados en esta revista están sujetos - si no se indica lo contrario - a una licencia de Reconocimiento 3.0 España de Creative Commons. Puede compartirlos con terceros siempre que reconozca su autoría, la publicación inicial en esta revista y las condiciones de la licencia. 